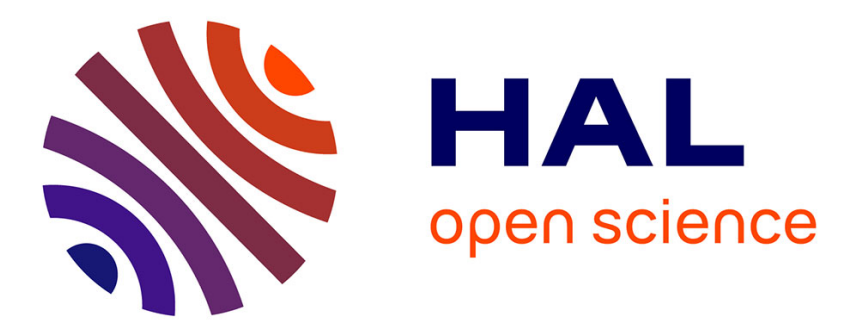

\title{
Specific surface area of carbon nanotubes and bundles of carbon nanotubes
}

Alain Peigney, Christophe Laurent, Emmanuel Flahaut, Revathi Bacsa, Abel Rousset

\section{- To cite this version:}

Alain Peigney, Christophe Laurent, Emmanuel Flahaut, Revathi Bacsa, Abel Rousset. Specific surface area of carbon nanotubes and bundles of carbon nanotubes. Carbon, 2001, vol. 39, pp. 507-514. 10.1016/S0008-6223(00)00155-X . hal-01003709

\section{HAL Id: hal-01003709 \\ https://hal.science/hal-01003709}

Submitted on 10 Jun 2014

HAL is a multi-disciplinary open access archive for the deposit and dissemination of scientific research documents, whether they are published or not. The documents may come from teaching and research institutions in France or abroad, or from public or private research centers.
L'archive ouverte pluridisciplinaire HAL, est destinée au dépôt et à la diffusion de documents scientifiques de niveau recherche, publiés ou non, émanant des établissements d'enseignement et de recherche français ou étrangers, des laboratoires publics ou privés. 


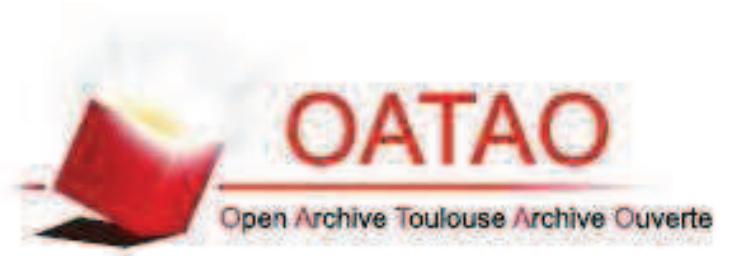

\section{Open Archive Toulouse Archive Ouverte (OATAO)}

OATAO is an open access repository that collects the work of Toulouse researchers and makes it freely available over the web where possible.

This is an author-deposited version published in: http://oatao.univ-toulouse.fr/ Eprints ID: 10718

To link to this article : DOI:10.1016/S0008-6223(00)00155-X

URL: http://dx.doi.org/10.1016/S0008-6223(00)00155-X

\section{To cite this version:}

Peigney, Alain and Laurent, Christophe and Flahaut, Emmanuel and Bacsa, Revathi and Rousset, Abel Specific surface area of carbon nanotubes and bundles of carbon nanotubes. (2001) Carbon, vol. 39 ( $\left.\mathrm{n}^{\circ} 4\right)$. pp. 507-514. ISSN $0008-6223$ 


\title{
Specific surface area of carbon nanotubes and bundles of carbon nanotubes
}

\author{
A. Peigney*, Ch. Laurent, E. Flahaut, R.R. Bacsa, A. Rousset \\ CIRIMAT, UMR CNRS 5085/LCMI, Centre Inter-universitaire de Recherche et d'Ingénierie des Matériaux, Université Paul-Sabatier, \\ F 31062 Toulouse cedex 4, France
}

\begin{abstract}
The theoretical external specific surface area of single- and multi-walled carbon nanotubes and of carbon nanotube bundles is calculated as a function of their characteristics (diameter, number of walls, number of nanotubes in a bundle). The results are reported in diagrams and tables useful to correlate the microscopic characteristics and the specific surface area of samples. The calculated values are in good agreement with the microscopic characteristics and the specific surface area measurements which have been previously reported in the literature. The specific surface area is a macroscopic parameter which can be helpful to adjust the synthesis conditions of carbon nanotubes.
\end{abstract}

Keywords: A. Carbon nanotubes; C. BET surface area; D. Surface areas

\section{Introduction}

Carbon nanotubes (hereafter denoted as CNTs) have unique properties [1] owing to their particular structure and are thus among the probable constituents of future materials. However, great quantities of well-characterized and reproducible CNTs are needed to prepare such novel materials. For this reason, many research groups are working towards the low-cost, large-scale synthesis of CNTs. In particular, the catalytic decomposition of hydrocarbons or $\mathrm{CO}$ over metal nanoparticles, also called carbon chemical vapour deposition (CCVD), is widely explored with the aim to maximize the proportion of single-walled nanotubes (SWNTs) in the products. The method is well known for the synthesis of carbon fibres (see Ref. [2] for a review) and at first, specimens containing mostly multiwalled nanotubes (MWNTs) with large diameters (15-40 $\mathrm{nm}$ ) and multiple walls were prepared. More recently, some works have shown that SWNTs can also be obtained [3-13]. The main difficulty is to optimise the synthesis conditions and the catalyst materials in order to avoid the formation of fibres and MWNTs. Very often, only scanning

\footnotetext{
*Corresponding author. Tel.: +33-561-556-175; fax: +33561-556-163.

E-mail address: peigney@iris.ups-tlse.fr (A. Peigney).
}

electron microscopy (SEM), transmission electron microscopy (TEM) and high-resolution electron microscopy (HREM) observations are used for the characterization $[3,5-7,9]$, sometimes in combination with Raman scattering which also brings some information on the diameter of SWNTs [8]. However, the use of a measurable macroscopical parameter such as the specific surface area, in addition to more local techniques, has been found to be very helpful [4,10-13].

Owing to its nanometric diameter, a CNT has a very large specific surface area (denoted as SSA hereafter). In materials science, the SSA of macroscopic samples of powders or porous materials is routinely determined by the measurement of gas adsorption (generally $\mathrm{N}_{2}$ at $77 \mathrm{~K}$ ) and calculations using the Brunauer-Emmett-Teller (BET) isotherm. This method is not destructive. Many authors have conducted SSA measurements on carbon filaments and have correlated the measured values with the microscopical characteristics and/or synthesis parameters $[2,14,15]$. Some researchers have reported such measurements on CNTs specimens $[16,17]$. Other workers have studied the adsorption of $\mathrm{N}_{2}$ at $77 \mathrm{~K}$, from which the external and internal SSA were calculated, showing that open MWNTs are mesoporous [18] whereas open SWNTs are microporous [19].

In the present paper, we report geometrical calculations 
establishing the relations between the theoretical external SSA of CNTs and their characteristics (diameter and number of walls). Calculations were also done for the SSA of CNT bundles, as a function of the number and characteristics of individual CNTs in the bundles. The results are reported in the form of diagrams and tables which may be useful to other researchers. It is furthermore shown that the previously reported measured SSA of CNT specimens are in good agreement with the theoretical SSA, which has been estimated or calculated on the basis of the microscopic characteristics reported by the respective authors. We also give some examples on how the SSA measurements have been very efficient to optimize the parameters of a CCVD method [4,10-13]. Thus, it is demonstrated that the SSA is a macroscopic parameter which cheaply and rapidly provides useful information on the microscopic characteristics of CNT specimens and is thus very helpful to adjust synthesis conditions of CNTs.

\section{Calculations and diagrams}

\subsection{Specific surface area of individual CNTs}

The calculations are based on the following hypotheses: (i) all CNTs are closed, and thus only the external surface of each CNT is taken into account, (ii) the length of the $\mathrm{C}-\mathrm{C}$ bonds in the curved graphene sheets is the same as in the planar sheet i.e. $d_{\mathrm{C}-\mathrm{C}}=0.1421 \mathrm{~nm}$ (Fig. 1a), (iii) the MWNTs are composed of concentric shells (Fig. 1b) and the inter-shell distance is $d_{\mathrm{s}-\mathrm{s}}=0.3400 \mathrm{~nm}$, (iv) the aspect ratio of CNTs is sufficiently high $(>1000)$ to neglect the area of the tip surfaces in comparison to the area of the cylindrical surfaces.

The surface area $\left(s_{\mathrm{h}}\right.$ - Fig. 1a) of one hexagon is: $s_{\mathrm{h}}=3 d_{\mathrm{C}-\mathrm{C}}^{2} \frac{\sqrt{3}}{2}=5.246 \times 10^{-20} \mathrm{~m}^{2}$.

$S_{\mathrm{h}}$ corresponds to two carbon atoms whose weight is, taking into account the atomic weight of carbon $\left(M_{\mathrm{C}}=\right.$ $12.01 \mathrm{~g} / \mathrm{mol})$ and the Avogadro number $\left(\mathcal{N}=6.023 \times 10^{23}\right.$ $\left.\mathrm{mol}^{-1}\right)$ :

$w_{\mathrm{h}}=\left(2 M_{\mathrm{C}} / \mathcal{N}\right)=3.988 \times 10^{-23} \mathrm{~g}$.

Combining (1) and (2) gives the specific surface area of one side of a graphene sheet (GS):

$\mathrm{SSA}(\mathrm{GS})=\frac{s_{\mathrm{h}}}{w_{\mathrm{h}}}=1315 \mathrm{~m}^{2} / \mathrm{g}$

It follows that the SSA of a SWNT is that of one side of a graphene sheet, whatever its diameter:

$\operatorname{SSA}(\operatorname{SWNT})=1315 \mathrm{~m}^{2} / \mathrm{g}$.

We now consider a MWNT (Fig. 1b) with an external diameter $d_{\mathrm{e}}$, a length $L$ and a number of shells $n$. Its external surface is:

$s_{\mathrm{MW}}=\pi L d_{\mathrm{e}}$.

The weight of this MWNT $\left(w_{\mathrm{MW}}\right)$ can be easily calculated from the surface of the external and internal graphene sheets $\left(s_{\mathrm{GS}}\right)$ which compose it, taking into account the surface weight of the graphene sheet $\left(w_{\mathrm{GS}}\right)$ :

$w_{\mathrm{MW}}=w_{\mathrm{GS}} \cdot s_{\mathrm{GS}}$

with

$w_{\mathrm{GS}}=\frac{1}{\mathrm{SSA}(\mathrm{GS})}=\frac{1}{1315}=7.602 \times 10^{-4} \mathrm{~g} / \mathrm{m}^{2}$.

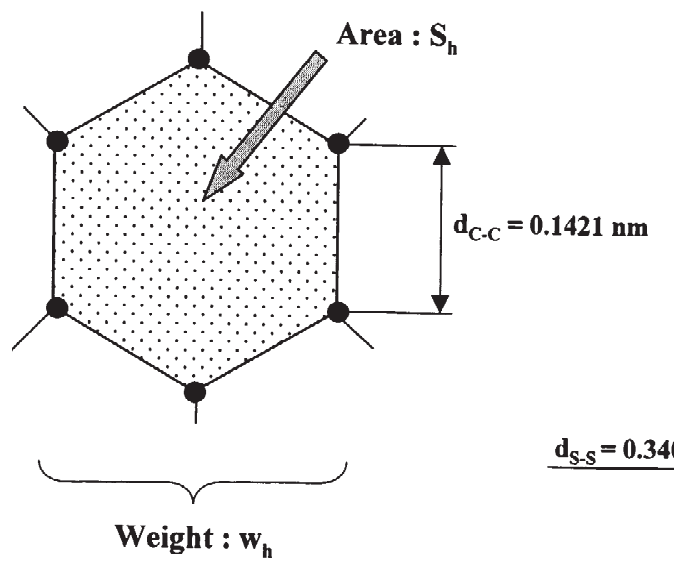

(a)

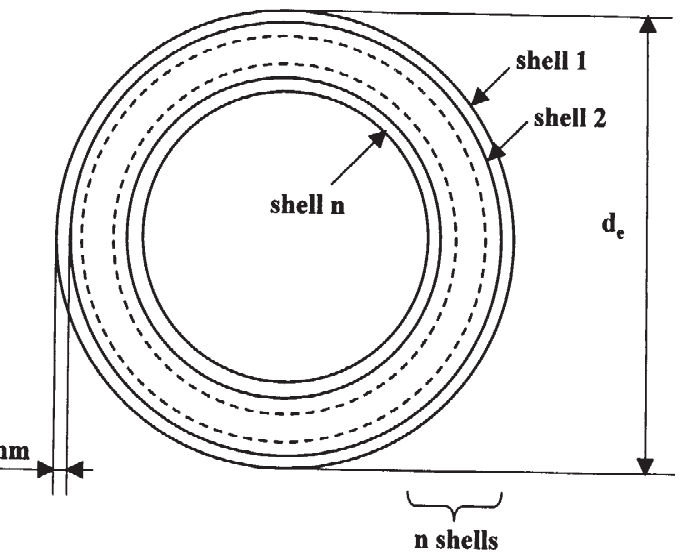

(b)

Fig. 1. Schematic representation of the arrangement of carbon atoms within the graphene layer (a) and of a multi-walled carbon nanotube made up of concentric graphene shells (b). 
The surface of all the graphene sheets which compose the MWNT is:

$$
\begin{aligned}
s_{\mathrm{GS}}= & \pi \cdot L \cdot d_{\mathrm{e}}+\pi \cdot L\left(d_{\mathrm{e}}-2 d_{\mathrm{s}-\mathrm{s}}\right)+\pi \cdot L\left(d_{\mathrm{e}}-4 \cdot d_{\mathrm{s}-\mathrm{s}}\right)+\cdots \\
& \cdot+\pi \cdot L\left[d_{\mathrm{e}}-(n-1) \cdot d_{\mathrm{s}-\mathrm{s}}\right],
\end{aligned}
$$

the different terms successively representing the surface of the external shell (number 1), of the first internal shell (number 2) and so on up to the innermost shell (n). This expression can be simplified:

$s_{\mathrm{GS}}=\pi L\left[n d_{\mathrm{e}}-2 d_{\mathrm{s}-\mathrm{s}} \sum_{i=1}^{n-1} i\right]$.

The specific surface area of the MWNT is:

$\operatorname{SSA}(\mathrm{MWNT})=\frac{s_{\mathrm{MW}}}{w_{\mathrm{MW}}}$

Combining with Eqs. (4)-(7) gives:

$$
\operatorname{SSA}(\mathrm{MWNT})=\frac{\mathrm{SSA}(\mathrm{GS}) \cdot d_{\mathrm{e}}}{n d_{\mathrm{e}}-2 d_{\mathrm{s}-\mathrm{s}}\left[\sum_{i=1}^{n-1} i\right]}
$$

and thus

$$
\operatorname{SSA}(\mathrm{MWNT})=\frac{1315 \cdot d_{\mathrm{e}}}{n d_{\mathrm{e}}-0.68\left[\sum_{i=1}^{n-1} i\right]}
$$

where $n \geq 2, d_{\mathrm{e}}$ is in $\mathrm{nm}$ and $\mathrm{SSA}(\mathrm{MW})$ is in $\mathrm{m}^{2} / \mathrm{g}$.

The SSA of CNTs is plotted versus the diameter for different numbers of shells (Fig. 2). The internal diameters were considered to be in the range $0.7-10 \mathrm{~nm}$. The SSA values are scattered on a very broad scale, from $1315 \mathrm{~m}^{2} / \mathrm{g}$ for SWNTs to about $50 \mathrm{~m}^{2} / \mathrm{g}$ for a MWNT $35 \mathrm{~nm}$ in diameter with 40 walls. Fig. $2 b$ and c are enlarged charts of Fig. 2a.

It appears that the number of shells is the predominant parameter influencing the SSA $\left(1315 \mathrm{~m}^{2} / \mathrm{g}\right.$ for SWNTs, $680-850 \mathrm{~m}^{2} / \mathrm{g}$ for $2 \mathrm{WNTs}, 295-430 \mathrm{~m}^{2} / \mathrm{g}$ for $5 \mathrm{WNTs}$, etc.) because each shell addition does not provoke a strong increase of the surface area of the CNT but causes a much larger increase of its weight. The diameter influences also the SSA of MWNTs (Fig. 2b and c), but to a lesser extent than the number of shells.

\subsection{Specific surface area of bundles of CNTs}

SWNTs and small MWNTs are seldomly obtained isolated but most often form bundles, either because they have grown in this configuration from a single catalytic particle, or because Van der Waals forces made them gather after each has grown from an individual catalytic particle. Thus, it is necessary to calculate the reduction of SSA due to the formation of the bundles. We consider that each bundle is composed of $N$ identical carbon nanotubes, of diameter $d_{\mathrm{e}}$, which are perfectly arranged in a triangular network (Fig. 3). In agreement with the measurements of Ge and Satller [20], the distance between two adjacent CNTs is assumed to be $d_{\mathrm{s}-\mathrm{s}}=0.3400 \mathrm{~nm}$. The surface area of a bundle made up of $N$ CNTs (SSBN) consists only of the part of the accessible surface of each CNT. An example is given in Fig. 3 for $N=3$. We assume that the surface of the individual CNTs corresponding to the inner surface of the bundle (the dashed lines in Fig. 3) is not accessible to the adsorbate and therefore will not be included in the calculations of SSB3.

The surface area of a bundle made up of only two CNTs (Fig. 4a) is SSB2 $=2$ SSNT. For three CNTs (Fig. 3 and Fig. 4b):

$\mathrm{SSB} 3=3 \mathrm{SSNT}-3 \frac{\pi / 3}{2 \pi} \mathrm{SSNT}=2.5 \mathrm{SSNT}$.

Starting with a bundle composed of two CNTs, each added CNT produces an SSBN increase equal to 0.5 SSNT, up to a total of six CNTs (Fig. 4c):

$\mathrm{SSBN}=[2+0.5(N-2)] \mathrm{SSNT}$ where $3 \leq N \leq 6$.

However, the surface area of the bundle remains equal to 4 SSNT when the 7th CNT is added (Fig. 4d). This corresponds to the completion of the first layer (noted as $\left.N^{\prime}=1\right)$ surrounding the original CNT.

We can define $N_{\text {eq }}$ as the number of individual CNTs with a total SSA equal to that of a bundle made up of $N$ CNTs. This equivalent number $N_{\text {eq }}$ is easily calculated for each CNT addition (Fig. 5, Table 1).

Moreover, when $N$ identical CNTs gather to form a perfect bundle (i.e. $N^{\prime}$ full layers), the SSA is modified by a correction factor $f=N_{\mathrm{eq}} / N$ (Table 2). $f$ decreases when more layers are added to the bundle, as illustrated by the following examples:

$f=\frac{4}{7}=0.571$ for $N^{\prime}=1(7 \mathrm{CNTs})$,

$f=\frac{7}{19}=0.368$ for $N^{\prime}=2(19 \mathrm{CNTs})$.

A particular value of $N^{\prime}$ corresponds to a value of the ratio $d_{\mathrm{b}} / d_{\mathrm{e}}$, were $d_{\mathrm{b}}$ is the diameter of the bundle and $d_{\mathrm{e}}$ that of the individual CNTs (Table 2). Since counting the CNTs within a bundle is possible only on a HREM image of the cross section of a bundle, which is sometimes difficult to obtain, the ratio $d_{\mathrm{b}} / d_{\mathrm{e}}$ is more easily obtained from the images than the number of layers $N^{\prime}$.

In the case of bundles of SWNTs, SSBN depends only on the number of the involved SWNTs according to the expression:

$\mathrm{SSBN}=\operatorname{SSA}(\mathrm{SWNT}) \cdot f=1315 f$

which gives $751 \mathrm{~m}^{2} / \mathrm{g}$ for a small bundle of seven SWNTs, $484 \mathrm{~m}^{2} / \mathrm{g}$ for a bundle made up of 19 SWNTs, and only $151 \mathrm{~m}^{2} / \mathrm{g}$ for a very large bundle composed of 217 SWNTs. 

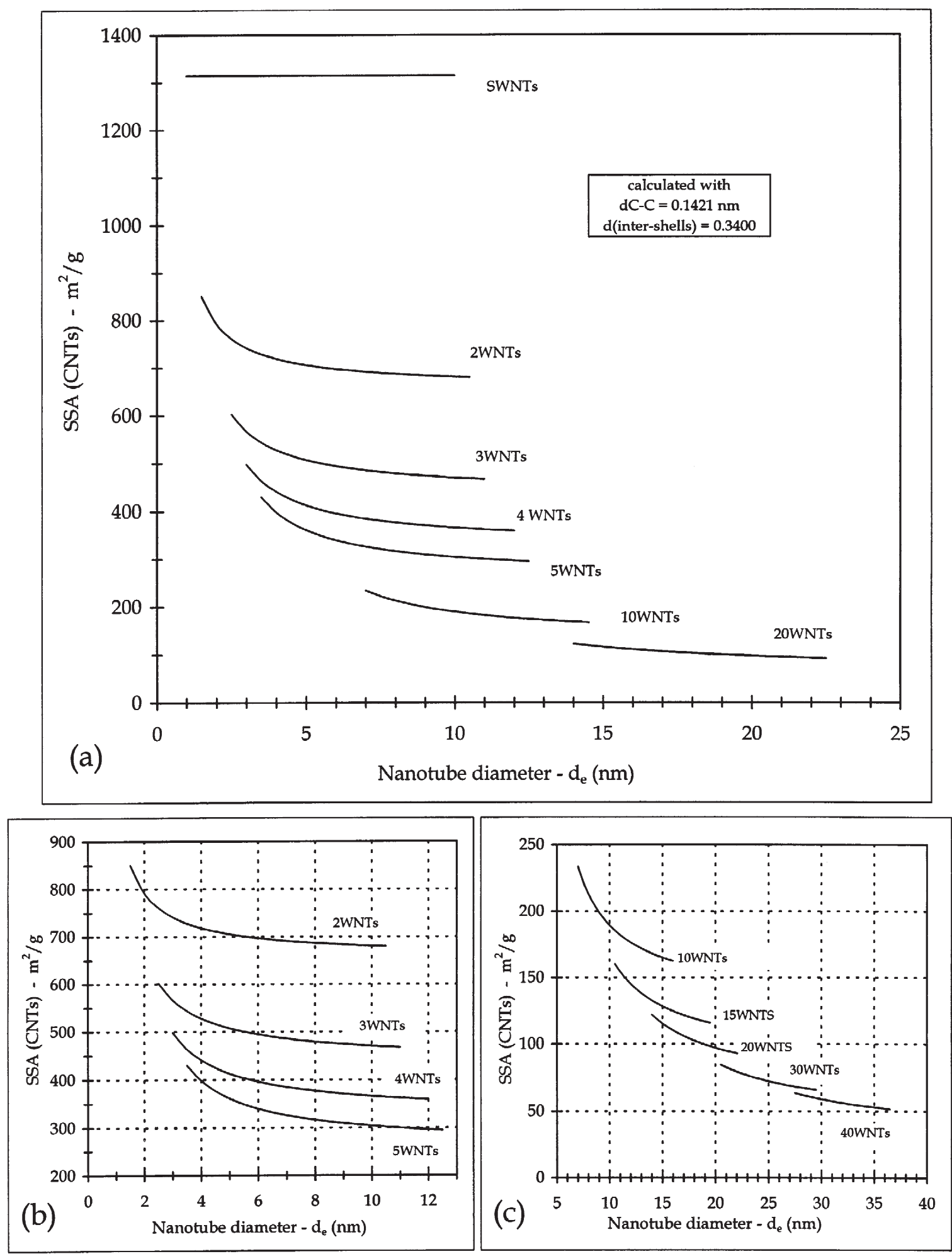

Fig. 2. Specific surface area of carbon nanotubes versus their diameter and number of walls.

\section{Discussion}

The previous calculations show that the theoretical SSA of CNTs are dispersed on a very broad scale, mainly depending on the number of walls and also on the diameter. In addition, the SSA of a CNTs bundle decreases when the number of CNTs which compose it increases. Thus, large MWNTs as well as nanofibers, which are not always tubular, will have a small SSA so far as they do not become porous $[2,14]$. Thus, one can conclude that max- 


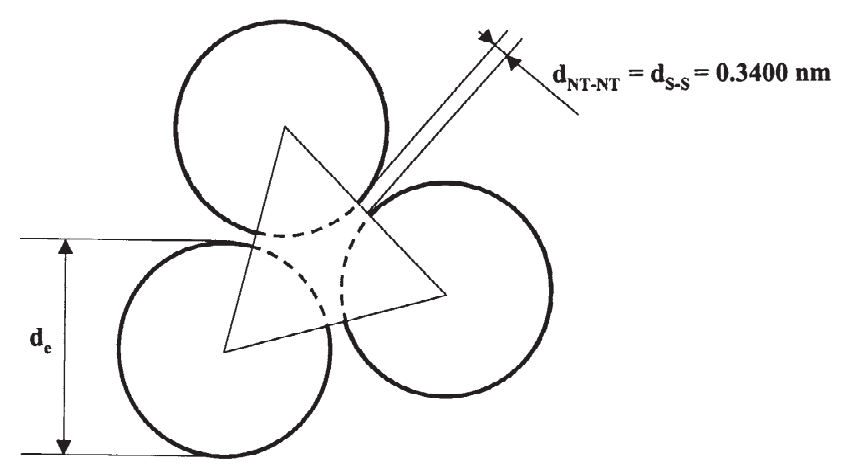

Fig. 3. Schematic representation of the triangular arrangement of carbon nanotubes within a bundle.

imizing the SSA is a good criterion to synthesize samples in which a majority of the carbon filaments are SWNTs or bundles of SWNTs and that the measure of the SSA can provide a good representation of the characteristics of the CNTs in the specimen under examination.

The present laboratory has made use of a method based on SSA measurements and carbon analysis [10-13], in addition to electron microscopy observations, to optimize the synthesis parameters of an original CCVD method [4]. The catalytic metal nanoparticles are obtained by selective reduction of an oxide solid solution in $\mathrm{H}_{2}-\mathrm{CH}_{4}$ and are thus immediately available for CNT nucleation and growth at the appropriate temperature. A CNTs-metal-oxide composite powder is thus obtained. The study of the influence of the iron content in the starting $\alpha-\mathrm{Al}_{2-2 x} \mathrm{Fe}_{2 x} \mathrm{O}_{3}$ powders [10] showed that the higher SSA of carbon $\left(250 \mathrm{~m}^{2} / \mathrm{g}\right)$, that we called the best carbon quality, is obtained with only 5 cat. $\% \mathrm{Fe}$ (i.e. $x=0.5$ ). Iron contents higher than 10 cat.\% lead to much smaller SSA

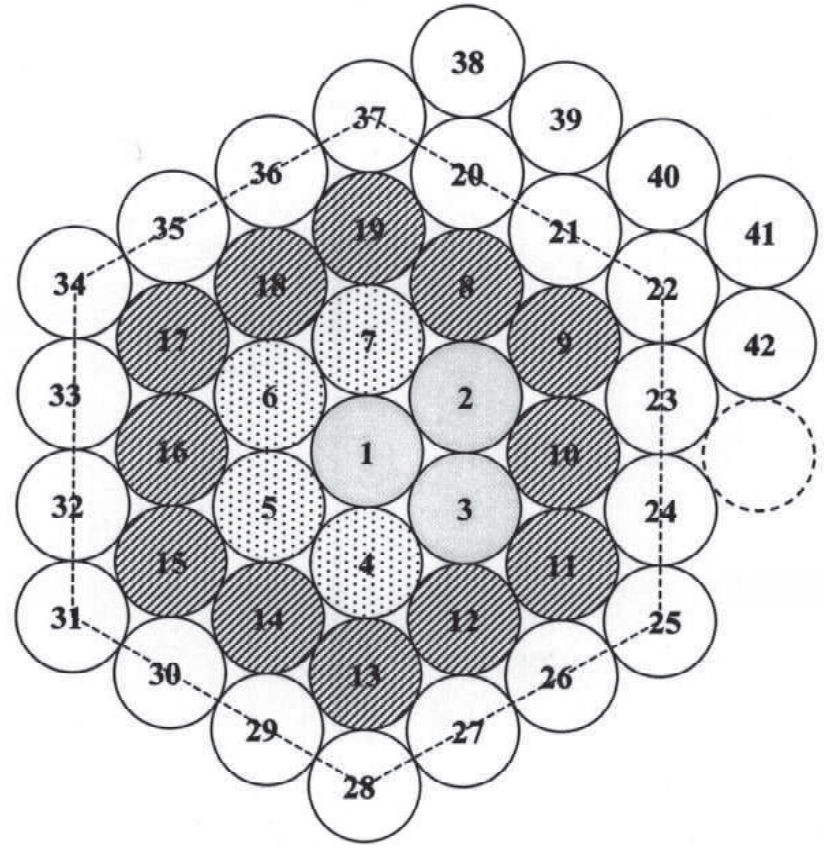

Fig. 5. Schematic representation of a bundle, showing the successive layers of carbon nanotubes which compose it.

$\left(<50 \mathrm{~m}^{2} / \mathrm{g}\right)$. Electron microscopy observations revealed that in high SSA samples, the filaments are only bundles of CNTs, whereas in low SSA samples most filaments are carbon nanofibers, with irregular surfaces, and much shorter than the CNT bundles. A study of the influence of the $\mathrm{CH}_{4}$ content in the $\mathrm{H}_{2}-\mathrm{CH}_{4}$ reducing gas mixture [11] revealed that the SSA of carbon is maximized $\left(230 \mathrm{~m}^{2} / \mathrm{g}\right)$ in the 9-18 mol.\% $\mathrm{CH}_{4}$ range. The observed filaments were CNTs, most having less than four walls, and generally
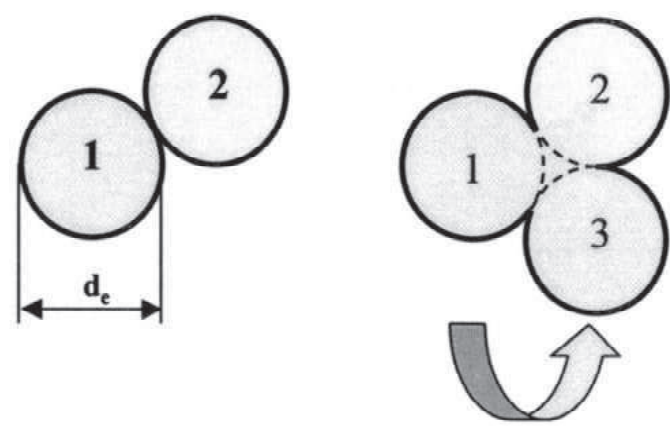

(a) (b)

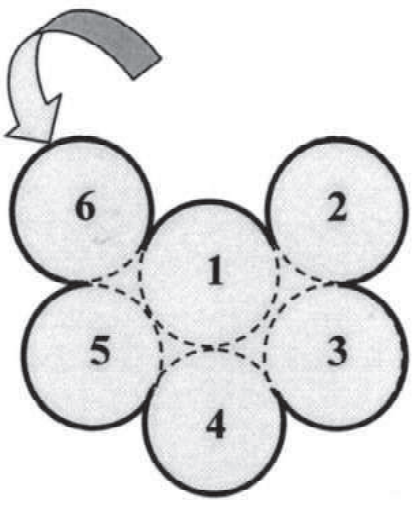

(c)

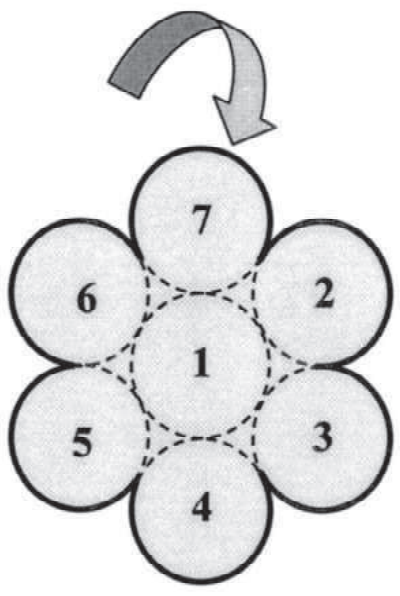

(d)

Fig. 4. Schematic representation of the formation of bundles by successive additions of carbon nanotubes. 
Table 1

Equivalent number $\left(N_{\mathrm{eq}}\right)$ of CNTs with a specific surface area equal to that of a bundle made up of $N$ CNTs, arranged in $N^{\prime}$ layers

\begin{tabular}{|c|c|c|c|c|c|c|c|c|c|c|c|c|c|c|c|c|c|c|c|}
\hline 1st layer & $N$ & 2 & 3 & 4 & 5 & 6 & 7 & & & & & & & & & & & & \\
\hline$\left(N^{\prime}=1\right)$ & $N_{\mathrm{eq}}$ & 2 & 2.5 & 3 & 3.5 & 4 & 4 & & & & & & & & & & & & \\
\hline 2nd layer & $N$ & 8 & 9 & 10 & 11 & 12 & 13 & 14 & 15 & 16 & 17 & 18 & 19 & & & & & & \\
\hline$\left(N^{\prime}=2\right)$ & $N_{\mathrm{eq}}$ & 4.5 & 5 & 5 & 5.5 & 5.5 & 6 & 6 & 6.5 & 6.5 & 7 & 7 & 7 & & & & & & \\
\hline 3rd layer & $N$ & 20 & 21 & 22 & 23 & 24 & 25 & 26 & 27 & 28 & 29 & 30 & 31 & 32 & 33 & 34 & 35 & 36 & 37 \\
\hline$\left(N^{\prime}=3\right)$ & $N_{\mathrm{eq}}$ & 7.5 & 7.5 & 8 & 8 & 8 & 8.5 & 8.5 & 8.5 & 9 & 9 & 9 & 9.5 & 9.5 & 9.5 & 10 & 10 & 10 & 10 \\
\hline 4th layer & $N$ & 38 & 39 & 40 & 41 & 42 & 43 & 44 & 45 & 46 & 47 & 48 & 49 & 50 & 51 & 52 & 53 & 54 & 55 \\
\hline$\left(N^{\prime}=4\right)$ & $N_{\text {eq }}$ & 10.5 & 10.5 & 10.5 & 11 & 11 & 11 & 11 & 11.5 & 11.5 & 11.5 & 11.5 & 12 & 12 & 12 & 12 & 12.5 & 12.5 & 12.5 \\
\hline
\end{tabular}

arranged in very long bundles. Starting from $\mathrm{Mg}_{1-x-y} \mathrm{M}_{x} \mathrm{M}_{y}^{\prime} \mathrm{Al}_{2} \mathrm{O}_{4}\left(\mathrm{M}, \mathrm{M}^{\prime}=\mathrm{Fe}, \mathrm{Co}, \mathrm{Ni}\right)$ solid solutions, it was shown $[12,13]$ that the SSA of carbon is maximal (about $350 \mathrm{~m}^{2} / \mathrm{g}$ ) when using only cobalt (i.e. $y=0)$, and for $x=0.1$. All filaments in that case are bundles of CNTs most of which are SWNTs.

We have separated the CNT bundles from the remaining part of the material by dissolving the oxide substrate $(\mathrm{MgO})$ and part of the catalytic Co particles in $\mathrm{HCl}$ [21]. SEM observations have shown that the bundles are less than $20 \mathrm{~nm}$ in diameter and TEM observations revealed a distribution of the diameters and numbers of walls (Fig. 6). The measured SSA of carbon in the final sample was equal to $365 \mathrm{~m}^{2} / \mathrm{g}$. From the histograms (Fig. 6) and the diagrams (Fig. 2), we calculate that the theoretical SSA would be equal to $940 \mathrm{~m}^{2} / \mathrm{g}$ if all CNTs were individual. The ratio between the experimental and theoretical values is 0.39 , which corresponds to bundles of about $18 \mathrm{CNTs}$ (Table 1 ) and $d_{\mathrm{b}} / d_{\mathrm{e}}=5$ (Table 2). Using the average CNT diameter $(2.5 \mathrm{~nm})$ deduced from the histograms (Fig. 6), the bundle's diameter should be about $15 \mathrm{~nm}$, which is in good agreement with the results of SEM observations $(<20 \mathrm{~nm})$.

In a recent work, CNT specimens with a SSA of carbon of $948 \mathrm{~m}^{2} / \mathrm{g}$ were obtained by increasing the specific surface area of the precursor oxide and decreasing the amount of cobalt [22]. From the distributions of the numbers of walls and diameters of individual CNTs, we have calculated a SSA in the range $900-1000 \mathrm{~m}^{2} / \mathrm{g}$. This is in good agreement with the present experimental value $\left(948 \mathrm{~m}^{2} / \mathrm{g}\right)$ and HREM observations which show that most of CNTs are individual. However, it cannot be entirely ruled out that some CNTs are open-ended and hence that their inner surface area contributes to the experimental value of SSA. However, the increase of SSA due to the opening of some CNTs may be balanced by the decrease of SSA due to the gathering of some of the CNTs in bundles.

Hernadi et al. [16] prepared mixtures of SWNTs and MWNTs by CCVD on Co-zeolite catalyst. The measured SSA values were $653 \mathrm{~m}^{2} / \mathrm{g}$ for specimens where the zeolite was removed by HF treatment, and only $312 \mathrm{~m}^{2} / \mathrm{g}$ after a further purification by $\mathrm{KMnO}_{4}$ oxidation. The TEM and HREM observations revealed ropes of SWNTs and MWNTs having between 5 and 27 walls, and external diameters between 8 and $28 \mathrm{~nm}$. The theoretical SSA of such MWNTs is between 400 and $70 \mathrm{~m}^{2} / \mathrm{g}$ and if we consider that the bundles of SWNTs can have a SSA of the order of $300 \mathrm{~m}^{2} / \mathrm{g}$, then the reported value of $312 \mathrm{~m}^{2} / \mathrm{g}$ is in acceptable agreement with the electron microscopy observations. However, $653 \mathrm{~m}^{2} / \mathrm{g}$ seems to be a very high value, showing that either some zeolite support could remain, or the SWNTs are almost individual at this stage of treatment, or a large majority of CNTs are open at their tips.

Inoue et al. [18] measured an external SSA of $178 \mathrm{~m}^{2} / \mathrm{g}$ for a powder of commercial MWNTs (Hyperion Catalysis Int. Co.) and examined the characteristics of the MWNTs by HREM: inner diameter of $4.0 \pm 0.8 \mathrm{~nm}$ and average thickness of $3 \pm 1 \mathrm{~nm}$. From the diagrams in Fig. 2, it may be deduced a theoretical external SSA of $200 \mathrm{~m}^{2} / \mathrm{g}$ for the average MWNT (10 $\mathrm{nm}$ in external diameter and nine

Table 2

Correction factor $(f)$ used to calculate the specific surface area of bundles made up of $N$ identical CNTs, arranged in $N^{\prime}$ layers, from the specific surface area of the individual $\mathrm{CNT}^{\mathrm{a}}$

\begin{tabular}{lllllllll}
\hline$N^{\prime}$ & 1 & 2 & 3 & 4 & 5 & 6 & 7 & 8 \\
\hline$f=N_{\mathrm{eq}} / N$ & $4 / 7$ & $7 / 19$ & $10 / 37$ & $13 / 61$ & $16 / 91$ & $19 / 127$ & $22 / 169$ & $25 / 217$ \\
$d_{\mathrm{b}} / d_{\mathrm{e}}$ & 0.571 & 0.368 & 0.270 & 0.213 & 0.176 & 0.150 & 0.130 & 0.115 \\
\hline
\end{tabular}

\footnotetext{
${ }^{\mathrm{a}} N_{\mathrm{eq}}$, equivalent number of CNTs (see text and Table 1). $d_{\mathrm{b}}$ and $d_{\mathrm{e}}$ are the diameters of the bundle and the individual CNT, respectively.
} 

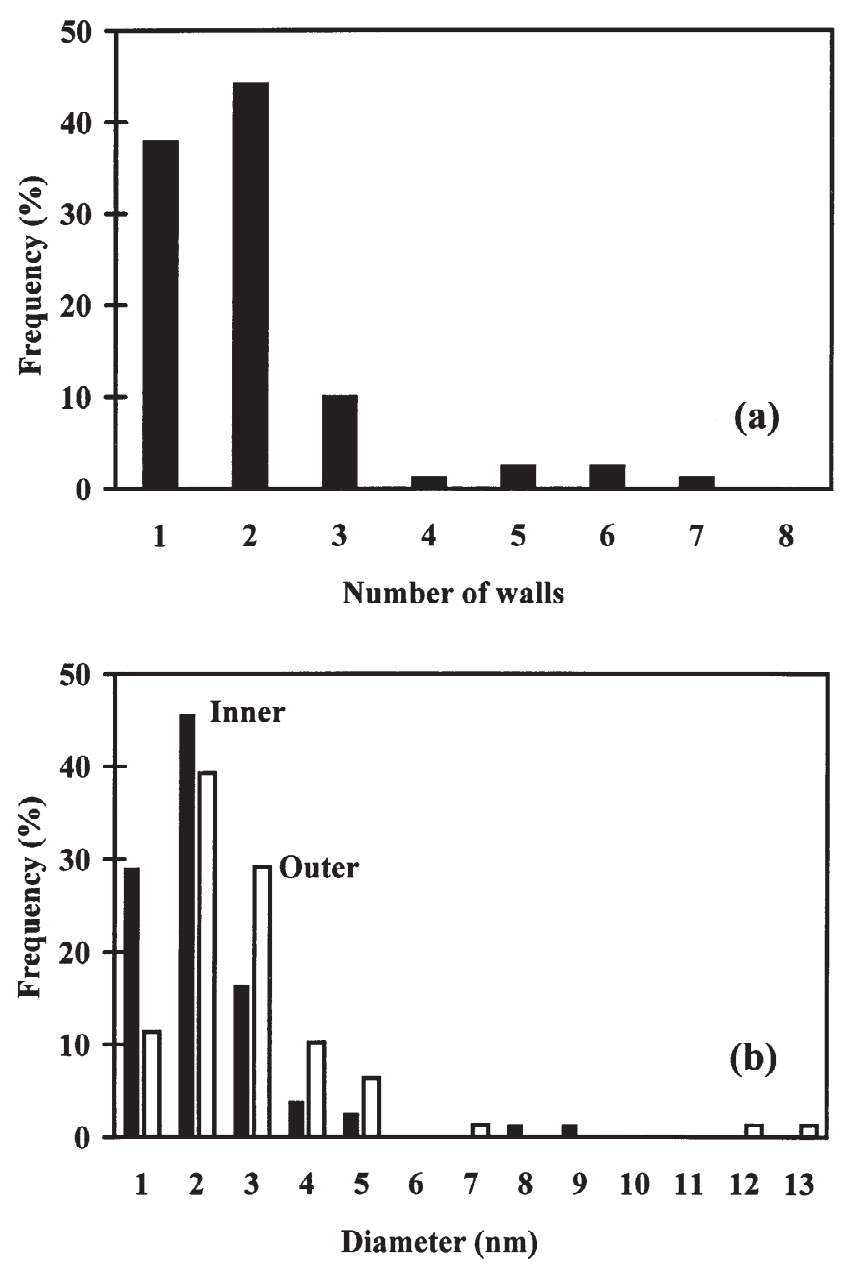

Fig. 6. Distribution of the number of walls (a) and of the inner and outer diameters (b) of the carbon nanotubes using data from HREM images, for a specimen prepared in the authors laboratory by a CCVD method [22].

walls), or in the $170-280 \mathrm{~m}^{2} / \mathrm{g}$ range if one takes into account the uncertainties on the diameter and thickness of the average MWNT. The distributions of the numbers of walls and diameters of MWNTs in the sample would be necessary to lead to a more precise determination of the theoretical SSA. The measured value $\left(178 \mathrm{~m}^{2} / \mathrm{g}\right)$ is in the lower part of the calculated range, which could be explained by two reasons. Firstly, the aggregation of the CNTs reported by the authors [18] could be only partially dissociated by the ultrasonic agitation. Secondly, some catalytic metal particles covered with carbon probably subsist in the samples.

Ye et al. [17] measured a SSA of $285 \mathrm{~m}^{2} / \mathrm{g}$ for a sample made of bundles of SWNTs, each $1.3 \mathrm{~nm}$ in diameter. The ratio between the experimental and theoretical values is ca. 0.22 . From Table 2, we deduce that this value corresponds to bundles made of four layers of CNTs, i.e. about 60 SWNTs, with a diameter nine times larger than the diameter of a SWNT $(1.3 \mathrm{~nm})$, i.e. about $11.7 \mathrm{~nm}$. These values are in good agreement with the microscopy observations [17] showing bundles about $10 \mathrm{~nm}$ in diameter, made up of ca. 50 SWNTs.

\section{Conclusions}

The theoretical external specific surface area of CNTs has been calculated as a function of their number of walls and diameter. Also, the theoretical specific surface area of CNT bundles has been calculated as a function of the number and characteristics of the CNTs which compose them. The theoretical specific surface area range over a very broad scale, from 50 to $1315 \mathrm{~m}^{2} / \mathrm{g}$. The value mostly depends on the number of walls. The measured specific surface areas of CNTs samples which have been previously reported in the literature are in good agreement with the theoretical specific surface area values determined from the microscopic characteristics described by the respective authors. Moreover, specific surface area measurements have been efficiently used by the present authors to optimize the synthesis of CNTs. Thus, the specific surface area is a macroscopic parameter, relatively easy to measure, which gives a good representation of the characteristics of CNTs, either isolated or in bundles.

\section{References}

[1] Dresselhaus MS, Dresselhaus G, Eklund PC. In: Science of Fullerenes and Carbon Nanotubes, San Diego: Academic Press, 1995, p. 20.

[2] Rodriguez NM. A review of catalytically grown carbon nanofibers. J Mater Res 1993;8(12):3233-50.

[3] Dai H, Rinzler AG, Nikolaev P, Thess A, Colbert DT, Smalley RE et al. Single-wall nanotubes produced by metalcatalyzed disproportionation of carbon monoxide. Chem Phys Lett 1996;260:471-5.

[4] Peigney A, Laurent Ch, Dobigeon F, Rousset A. Carbon nanotubes grown in situ by a novel catalytic method. J Mater Res 1997;12:613-5.

[5] Hafner JH, Bronikowski MJ, Azamian BK, Nikolaev P, Rinzler AG, Colbert DT et al. Catalytic growth of singlewall carbon nanotubes from metal particles. Chem Phys Lett 1998;296:195-202.

[6] Kong J, Cassell AM, Dai H. Chemical vapor deposition of methane for single-walled carbon nanotubes. Chem Phys Lett 1998;292:567-74.

[7] Cassell AM, Raymakers JA, Kong J, Dai H. Large scale CVD synthesis of single-walled carbon nanotubes. J Phys Chem B 1999;103(3):6484-92.

[8] Cheng HM, Li F, Sun X, Brown SDM, Pimenta MA, Marucci A et al. Bulk morphology and diameter distribution of single-walled carbon nanotubes synthesized by catalytic decomposition of hydrocarbons. Chem Phys Lett 1998;289:602-10.

[9] Colomer JF, Bister G, Willems J, Konya Z, Fonseca A, Van Tendeloo G, Nagy JB. Synthesis of single-wall carbon 
nanotubes by catalytic decomposition of hydrocarbons. Chem Commun 1999;:1343-4.

[10] Peigney A, Laurent Ch, Dumortier O, Rousset A. Carbon nanotubes- $\mathrm{Fe}-\mathrm{Al}_{2} \mathrm{O}_{3}$ nanocomposites. Part $\mathrm{I}$ : influence of the $\mathrm{Fe}$ content on powder synthesis. J Eur Ceram Soc 1998; 18:2005-13.

[11] Peigney A, Laurent Ch, Rousset A. Influence of the composition of the $\mathrm{H}_{2}-\mathrm{CH}_{4}$ gas mixture on the catalytic synthesis of carbon nanotubes- $\mathrm{Fe} / \mathrm{Fe}_{3} \mathrm{C}-\mathrm{Al}_{2} \mathrm{O}_{3}$ nanocomposite powders. J Mater Chem 1998;9:1167-77.

[12] Govindaraj A, Flahaut E, Laurent Ch, Peigney A, Rousset A, Rao CNR et al. An investigation of carbon nanotubes obtained from the decomposition of methane over reduced $\mathrm{Mg}_{1-x} \mathrm{M}_{x} \mathrm{Al}_{2} \mathrm{O}_{4}(\mathrm{M}=\mathrm{Fe}, \mathrm{Co}, \mathrm{Ni})$ spinel catalysts. J Mater Res 1999;14:2567-76.

[13] Flahaut E, Govindaraj A, Peigney A, Laurent Ch, Rousset A, Rao CNR et al. Synthesis of single-walled carbon nanotubes using binary $(\mathrm{Fe}, \mathrm{Co}, \mathrm{Ni})$ alloy nanoparticles prepared in situ by the reduction of oxide solid solutions. Chem Phys Lett 1999;300:236-42.

[14] Walker Jr. PL, Rakszawski JF, Imperial GR. Carbon formation from carbon monoxide-hydrogen mixtures over iron catalysts. J Phys Chem 1958;63:133-49.

[15] Park C, Rodriguez NM, Baker RTK. Carbon deposition on iron-nickel during interaction with carbon monoxide-hydrogen mixtures. J Catal 1997;169:212-27.

[16] Hernadi K, Fonseca A, Nagy JB, Bernaerts D, Fudala A, Lucas AA et al. Catalytic synthesis of carbon nanotubes using zeolite support. Zeolites 1996;17:416-23.

[17] Ye Y, Ahn CC, Witham C, Fultz B. Hydrogen adsorption and cohesive energy of single-walled carbon nanotubes. Appl Phys Lett 1999;74(16):2307-9.

[18] Inoue $\mathrm{S}$, Ichikuni $\mathrm{N}$, Susuki $\mathrm{T}$, Uematsu $\mathrm{T}$, Kaneko $\mathrm{K}$. Capillarity condensation of $\mathrm{N}_{2}$ on multiwall carbon nanotubes. J Phys Chem B 1998;102(24):4689-92.

[19] Eswaramoorthy M, Sen R, Rao CNR. A study of micropores in single-walled carbon nanotubes by the adsorption of gases and vapors. Chem Phys Lett 1999;304:207-10.

[20] Ge M, Satller K. Vapor-phase grown bundles of carbon nanotubes. Mater Res Soc Symp Proc 1994;349:313-7.

[21] Flahaut E, Peigney A, Laurent Ch, Rousset A. Synthesis of single-walled carbon nanotube- $\mathrm{Co}-\mathrm{MgO}$ composite powders and extraction of the nanotubes. J Mater Chem 2000;10(2):249-52.

[22] Bacsa RR, Laurent Ch, Peigney A, Bacsa WS, Vaugien Th, Rousset A. High specific surface area carbon nanotubes from catalytic chemical vapor deposition process. Chem Phys Lett 2000; In press. 